\title{
DYNAPENIA AND METABOLIC HEALTH IN OBESE AND NON-OBESE OLDER ADULTS AGED 70 YEARS AND OLDER: THE LIFE STUDY
}

\section{Authors:}

Aubertin-Leheudre $\mathrm{M}^{1,2}$, Anton $\mathrm{S}^{1}$, Beavers DP3; Manini TM${ }^{1}$, Fielding R4; Newman $\mathrm{A}^{5}$; Church $\mathrm{T}^{6}$;

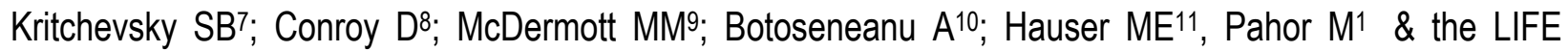
Research Group.

1Department of Aging and Geriatric Research, University of Florida, Gainesville, FL 32611, USA.

2 Department of Sciences of Physical Activity, Université du Québec à Montréal; CRIUGM; Montréal Québec, H2X1Y4 Canada.

${ }^{3}$ Department of Biostatistical Sciences, Wake Forest School of Medicine, Winston-Salem, NC 27157, USA. ${ }^{4}$ Nutrition, Exercise Physiology, and Sarcopenia Laboratory, Jean Mayer USDA Human Nutrition Research Center on Aging, Tufts University, Boston, Massachusetts, USA

${ }^{5}$ Department of Epidemiology, University of Pittsburgh, Pennsylvania, USA

${ }^{6}$ Preventive Medicine Laboratory, Peninngton Biomedical Research Center, Baton Rouge, LA 70808, USA.

${ }^{7}$ Sticht Center on Aging, School of Medicine, Wake Forest University, Winston-Salem, North Carolina

8 Department of Kinesiology, Pennsylvania State University, University Park, Pennsylvania. Department of Preventive Medicine, Northwestern University, Evanston, Illinois

9 Department of Internal Medicine, Northwestern Medical Faculty Foundation, Chicago, IL 60611, USA

${ }^{10}$ Department of Internal Medicine, Yale School of Medicine, New Haven, CT 06510, USA

${ }^{11}$ Stanford Prevention Research Center, Stanford University, Palo Alto, CA 94304, USA

Corresponding Authors:

Mylène Aubertin-Leheudre, PhD

Key words: Muscle strength, Obesity, metabolic syndrome, Aging

Running Title: Dynapenia and Obesity as predictors of metabolic disorders 


\section{ABSTRACT}

Objective: The purpose of this study was to examine the relationship between dynapenia and metabolic risk factors in obese and non-obese older adults.

Methods: A total of 1453 men and women (age $\geq 70$ years) from the Lifestyle Interventions and Independence for Elders (LIFE) Study were categorized as (1) non-dynapenic/non-obese (NDYN-NO), (2) dynapenic/non-obese (DYN-NO), (3) non-dynapenic/obese (NDYN-O), or (4) dynapenic/obese (DYN-O), based on muscle strength (FNIH criteria) and body mass index. Dependent variables were blood lipids, fasting glucose, blood pressure, presence of at least three metabolic syndrome (MetS) criteria and other chronic conditions.

Results: A significantly higher likelihood of having abdominal obesity criteria in NDYN-NO compared to DYN-NO groups ( 55.6 vs $45.1 \%, p \leq 0.01$ ) was observed. Waist circumference was also significantly higher in obese groups (DYN-O $=114.0 \pm 12.9$ and $N D Y N-O=111.2 \pm 13.1$ ) than in non-obese (NDYN$\mathrm{NO}=93.1 \pm 10.7$ and DYN-NO=92.2 $\pm 11.2, p \leq 0.01)$; and higher in NDYN-O compared to DYN-O ( $p=$ 0.008). Additionally, NDYN-O demonstrated higher diastolic blood pressure compared to DYN-O $(70.9 \pm 10.1$ vs $67.7 \pm 9.7, p \leq 0.001)$. No significant differences were found across dynapenia and obesity status for all other metabolic components ( $p>0.05$ ). The odds of having metabolic syndrome or its individual components were similar in obese and non-obese, combined or not with dynapenia (non-significant $O R$ $[95 \% \mathrm{Cl}])$.

Conclusion: Non-obese dynapenic older adults had fewer metabolic disease risk factors than non-obese and non-dynapenic older adults. Moreover, among obese older adults, dynapenia was associated with lower risk of meeting metabolic syndrome criteria for waist circumference and diastolic blood pressure. Additionally, the presence of dynapenia did not increase cardiometabolic disease risk in either obese or non-obese older adults. 


\section{INTRODUCTION}

The prevalence of overweight and obesity have dramatically increased across all segments of society in over the past two decades, including older adults. Thirty-three percent of American adults age 60 and older are now considered obese [1]. This is of concern as obesity, particularly abdominal obesity, has been widely recognized as a predisposing factor to cardiovascular disease (CVD) and the metabolic syndrome [2]. Moreover, the prevalence of the metabolic syndrome shows a clear linear trend with age [3]. Currently, $53 \%$ of adults over age 65 years old have metabolic syndrome, compared with $18 \%$ of adults below age 40 [3].

Abdominal obesity is associated with an upregulation of pro-inflammatory cytokines, such as interleukin-6 and tumor necrosis factor-alpha [4,5], which may contribute to apoptosis in myocytes and lead to declines in muscle mass and strength. In addition, aging is independently associated with decreased muscle mass (sarcopenia) [6]. Some estimates indicate that 25 to $50 \%$ of adults aged 65 and older are sarcopenic [7]. This high prevalence of sarcopenia in older adults is concerning as low muscle mass is associated with the development of physical disabilities [8], as well as increased risk of hospitalization [9] and mortality. Sarcopenia may also contribute to metabolic complications and CVD in older adults [10, 11]. One potential explanation for these findings is that skeletal muscle atrophy is intricately linked to the metabolic alterations associated with physical inactivity and reduction of energy expenditure, which lead to insulin resistance [12]. In addition, sarcopenia is closely related to impairments in glucose homeostasis, underscoring the potential negative additive effects of low muscle mass, when combined with obesity, on glucose regulation and insulin resistance [13].

The impact of sarcopenia-obesity on the metabolic profile is poorly studied, which is surprising given the large percentage (8-25\%) of sarcopenic-obese individuals [14]. To our knowledge, the limited research that has been conducted on the combined effects of sarcopenia and obesity on metabolic risk factors and CVD in older adults has produced mixed findings [15-21]. Two studies [16, 17] indicate that sarcopenia-obesity has no particular deleterious impact on metabolic risk factors and CVD in Caucasian postmenopausal women. Conversely, in their review Prado et al. [18] showed that having low muscle mass and high fat mass increased CVD risk in Asian older adults. Yet another study by Castaneda et al [19] suggested that there may be health benefits associated with sarcopenia-obesity, as obese, sarcopenic older adults had reduced risk of diabetes compared to obese, non-sarcopenic older adults. Goulet et al. [22] also observed a better insulinemic profile in sarcopenic-obese postmenopausal women. Baumgartner [20] also reported that obese, sarcopenic elderly have less metabolic syndrome but higher rates of type II diabetes than either non-obese, sarcopenic or obese, non-sarcopenic older adults. Finally, Stephen et al. showed that sarcopenia, when combined with obesity, induced a modest increase in risk of CVD in community dwelling older men and women aged 65 years and older; this relationship was mediated mostly by muscle strength [23]. 
In addition to loss of muscle mass, a loss of muscle strength is also observed with aging [24]. Ageassociated loss of muscle strength, called dynapenia [25], occurred in $60 \%$ of adults aged 60 and older [26]. Dynapenia has been shown to be associated with poor cardio-respiratory function [27], a decline in mobility [8, 28], incident disability [29] and mortality [30,31]. There is some evidence of a direct association between metabolic syndrome and insulin resistance with low muscular strength [32, 33]; intramuscular adipose tissue (IMAT) [34] and high blood pressure [35].

Based on these previous observations, the combined effect of dynapenia and obesity would be predicted to contribute to a worse metabolic profile compared to either condition alone. Dynapenic-obese individuals represent 7.6 to $11.1 \%$ of older adults [23,36]. As for sarcopenia, only a few studies have been conducted on the effect of sarcopenic-obesity on metabolic risk factors and CVD in elderly people. Sénéchal et al. recently showed that the combination of abdominal obesity and dynapenia is associated with more metabolic alterations in adults 50 years of age and older (mean age: $65 \pm 10$ ) than dynapenia or obesity alone [37]. In addition, both abdominal obesity and low muscular strength are characterized by high circulating levels of pro-inflammatory cytokines which are recognized as risk factors for CVD [4]. Atlantis et al. [11] and Karelis et al [38] observed that low muscle strength was associated with insulin resistance in elderly obese people. However, Barbat-Artigas et al. [39, 40] reported that dynapenia status appeared to be associated with a better insulinemic profile in obese postmenopausal women.

To our knowledge, no study has examined the metabolic effects of dynapenia in obese and non-obese older adults (age $\geq 70$ years). Therefore, the purpose of this secondary analysis was to examine the relationship between dynapenia and metabolic risk factors in obese and non-obese adults aged 70 years and older who participated in the Lifestyle Interventions and Independence for Elders (LIFE) Study. We hypothesized that dynapenic older adults would have higher metabolic disease risk factors compared to non-dynapenic obese and non-obese older adults. 


\section{METHODS}

\section{Participants}

The LIFE Study eligibility criteria [41] targeted older persons, aged 70-89 years, who were: sedentary; at risk for mobility disability (SPPB score $\leq 10$ ); able to walk 400 meters $(\mathrm{m})$ in less than 15 minutes without sitting, using a walker, or needing the help of another person; and able to safely participate in the intervention. A total of 1,635 participants were recruited through eight field centers. Individuals with a Short Physical Performance Battery (SPPB) score below 7 were preferentially enrolled ( $45 \%$ of the sample) to enrich the sample with individuals at high risk for major mobility disability. For the present study, 147 of the 1635 participants were excluded because either handgrip or BMI measurements were not available. Thus, the total sample size for the present study was 1453 participants.

\section{Anthropometrics measurements}

Body weight, height, and waist circumference (WC) were measured during the baseline visit. Waist circumference was obtained horizontally at the midpoint between the highest point of the iliac crest and the lowest part of the costal margin in the mid-axillary line.

\section{Sociodemographic measurements}

Sociodemographic factors including age, race, education, income, and smoking were assessed by questionnaire at the screening interview.

\section{Physical activity (PA) measurements:}

The Community Healthy Activities Model Program for Seniors (CHAMPS) was used to assess self-reported PA [42]. The Actigraph triaxial accelerometer (Model GT3X; Actigraph Inc., Pensacola, FL) was used to objectively measure total PA time and total steps. The accelerometer was worn on the right hip during at least 3 consecutive days in free-living conditions. Activity was recorded using 1-second epochs, which were added up to minute-to-minute epochs. Non-wear time was defined as a 60-minute window of zero counts in all three axes, allowing for up to two minutes of nonzero counts $<100$ in the vertical axis. Data files with fewer than 10 hours per day of wear time were excluded [43].

\section{Self-reported chronic conditions.}

The following conditions were considered based on a self-reported questionnaire: arthritis, lung diseases (emphysema, asthma, or chronic bronchitis), and cardiovascular diseases (heart attack, or stroke). A score of 1 was given to each of the conditions when individuals answered positively. Global cognitive function was based on the Mini-Mental State Examination (3MS) [44]. Depressive symptoms were based on the Center for Epidemiological Studies-Depression Scale (Radloff LS).

\section{Groups Classification}




\section{$\underline{\text { Body mass index (BMI) }}$}

Body weight was measured to the nearest $0.1 \mathrm{~kg}$ using a calibrated scale with the participants wearing light clothes and no shoes. Body height was measured to the nearest millimeter using a wall-mounted stadiometer. BMI was calculated as body weight $(\mathrm{kg})$ divided by height $(\mathrm{m})$ squared $\left(\mathrm{kg} / \mathrm{m}^{2}\right)$. In our analyses, we used the clinical standard obesity BMI cut-point provided by the world health organization WHO $\left(\mathrm{BMl}>30 \mathrm{~kg} / \mathrm{m}^{2}\right)$.

\section{Grip strength / Dynapenia}

Right and left handgrip strengths were measured in kilograms using a handheld dynamometer (Jamar Handheld Dynamometer; J.A. Preston Corporation, Clifton, NJ). If the participant reported current flare-up of pain in the wrist or hand or had undergone fusion, arthroplasty, tendon repair, synovectomy, or other related surgery of the hand or wrist in the past 3 months, the affected side was not tested. Prior to data collection, a practice session was conducted to acquaint participants with the instrument and adjust it appropriately. Each measurement was made with the participant seated, elbow slightly flexed, wrist in a neutral position, and the interphalangeal joint of the index finger at a $90^{\circ}$ angle. The participant was instructed to squeeze the handle with maximal effort for 3-5 seconds. The measurement was repeated after a 10-second pause for recovery. The average of the two trials from the stronger hand was used in the analyses.

The dynapenia criteria was determined using the FNIH cut-points [45]: (1) non-dynapenic group (W: $\geq 20$; $\mathrm{M}: \geq 32$ ); (2) dynapenic group (19.9 $\leq \mathrm{W} ; 31.9 \leq \mathrm{M})$.

\section{Laboratory Assays}

Blood samples were collected in early morning, after a 12-hour fast. Blood sampling was postponed in the event of an acute infection. All blood was collected, processed, divided into aliquots, and stored locally at $-80^{\circ} \mathrm{C}$ until shipment to the Wake Forest University, where samples were stored for long term at $-80^{\circ} \mathrm{C}$ until analysis. Serum glucose and lipoprotein lipids were measured by the Esoterix Clinical Trial Services, a Division of LabCorp (Cranford, NJ), using enzymatic method.

\section{Definition of Metabolic Syndrome (MetS)}

The diagnosis of the MetS was based on the criteria of the National Cholesterol Education Program (Adult Treatment Panel III, NCEP ATP III) [46].

The MetS was diagnosed when three or more of the following were present: 1) waist circumference (WC) greater than or equal to $102 \mathrm{~cm}$ in men and greater than or equal to $88 \mathrm{~cm}$ in women, 2) triglycerides greater than or equal to $150 \mathrm{mg} / \mathrm{dL}$ or drug treatment for elevated triglycerides, 3) high-density lipoprotein cholesterol (HDL-C) less than $40 \mathrm{mg} / \mathrm{dL}$ in men and less than $50 \mathrm{mg} / \mathrm{dL}$ in women or drug treatment for low $\mathrm{HDL}$, 4) fasting glucose greater than or equal to $100 \mathrm{mg} / \mathrm{dL}$ or drug treatment for elevated glucose, and 5) systolic blood pressure (BP) greater than or equal to $130 \mathrm{mmHg}$ or diastolic BP greater than or equal to 85 $\mathrm{mmHg}$ or on antihypertensive drug treatment with a history of hypertension. 


\section{Statistical Analyses}

Continuous data are presented as unadjusted means and $S D$, whereas categorical variables are presented as counts and percentages. T-tests were used to identify differences in psycho-social characteristics (age, income, education level, race, gender, smoking status, comorbidities), grip strength, BMI, metabolic factors (WC, lipoprotein blood levels, blood pressure, glycemic blood level), metabolic criteria (NCEP ATP III), and level of physical activity (CHAMPS score, accelerometry) between dynapenic and non-dynapenic groups separately by obesity status. Partial correlation analyses for metabolic profiles were conducted adjusting for: age, BMI, gender, race, smoking status, education; physical activity levels and comorbidities (heart attack, lung disease, diabetes, and arthritis). Logistic regression was used to identify odd ratios for dichotomized dependent variables of the metabolic criteria. All regressions were adjusted for age, BMI, gender, race, smoking status, education; physical activity levels and comorbidities. Data management and statistical analyses were performed using SAS version 9.4 (SAS Institute, Cary, NC). 


\section{RESULTS}

\section{Baseline characteristics of participants (Table 1)}

The mean $( \pm$ SD) age of included participants was $78.8( \pm 5.3)$ years, $34 \%$ were men, and $21 \%$ were racial/ethnic minorities (non-white). Participants were divided into two groups based on obesity criteria. Thereafter, obese and non-obese participants were divided according to FNIH dynapenia criteria (dynapenic: $n=637$ vs non-dynapenic: $n=816$ ). Table 1 displays characteristics of participants according to dynapenia and obesity classification.

By definition, dynapenic-obese (DYN-O; $n=256$ ) and non-dynapenic obese (NDYN-O; $n=414$ ) groups had a higher BMI compared with dynapenic non-obese (DYN-NO; $n=381$ ) and non-dynapenic non-obese (NDYN-NO; $n=402$ ) individuals ( $p \leq 0.01$ ). In addition, DYN-O and DYN-NO groups had a lower handgrip strength (kg or kg/BW) compared with NDYN-O and NDYN-NO individuals ( $p \leq 0.01$ ). DYN-O and DYN-NO groups had a lower level of physical activity (counts) compared with NDYN-O and NDYN-NO individuals ( $p$ $\leq 0.01$ ). No difference regarding gender (\% of males), level of education, cognitive function (3MS) and some comorbidities (arthritis, diabetes etc.) were observed between the groups (see Table 1).

\section{Increased likelihood of MetS and its components according to dynapenia and obesity status (Table 2)}

We observed a significantly higher likelihood of having abdominal obesity criteria in NDYN-NO compared to DYN-NO groups $(p \leq 0.01)$. Waist circumference was also significantly higher in obese groups (DYNO/NDYN) than in non-obese (NDYN-NO/DYN-NO) $(p \leq 0.01$ ), and perhaps more interesting, waist circumference was also significantly higher in NDYN-O compared to DYN-O $(p=0.008)$. Additionally, NDYN-O had significantly higher diastolic blood pressure compared to DYN-O ( $p \leq 0.001)$. Regarding the metabolic components, no significant differences were found across dynapenia and obesity status for MetS, glucose, HDL, triglycerides, or systolic blood pressure. Finally, fasting glucose, triglycerides, HDL, LDL, total cholesterol, blood pressure (diastolic and systolic) did not differ between obese and non-obese participants.

\section{Correlation between grip strength and MetS components (Table 3)}

Except for $B M I$ ( $\left.p \leq 0.05 ; r^{2}=0.05\right)$ in the obese group, and for waist circumference in all individuals together ( $p \leq 0.05 ; r^{2}=0.03$ ), we observed no correlation between grip strength and continuously measured MetS components (glucose, blood pressure, TG, HDL, LDL) in all, obese and non-obese participants even after controlling for age, sex, and race/ethnicity. 


\section{The odds ratio of meeting MetS and its components}

Table 4 shows that odds of MetS was not significantly different between obese and non-obese groups, even when combined with dynapenia.

\section{DISCUSSION}

The aim of this study was to verify whether dynapenia affect metabolic risk factors in obese and non-obese older adults. Contrary to our hypothesis, our results demonstrated that non-dynapenic non-obese individuals, compared to dynapenic obese ones, have significantly higher risk of abdominal obesity. In addition, a lower prevalence of cardiovascular and metabolic disease risk factors (i.e. blood pressure and waist circumference) was observed in non-dynapenic compared to dynapenic obese people (Table 2\&3).

Moreover, the presence of dynapenia and obesity did not increase the odds of presenting metabolic disease risk factors (Table 2) which suggests that a lower level of muscle strength is associated with a favorable metabolic profile than higher levels of muscle strength in men and women aged 70 years and over. These findings are in agreement with those of Barbat-Artigas et al [40] which demonstrated that dynapenic-obese postmenopausal women (mean age $60 \pm 5 \mathrm{y}$ ) had a better metabolic profile than nondynapenic obese women, suggesting that dynapenia has a protective effect on metabolic risk in older adults. Similar conclusions were drawn regarding sarcopenia by Aubertin-Leheudre et al. [16]. This crosssectional study showed that sarcopenic-obese women had fewer metabolic risk factors predisposing to CVD than obese women (i.e. higher HDL levels, lower visceral and abdominal fat mass content, lower triglyceride levels and a better cholesterol/HDL-cholesterol ratio). In addition, sarcopenic women tended to have lower HOMA and fasting glucose levels. Finally, an epidemiological cross-sectional study including middle-aged individuals (40-75 years old) conducted by Castaneda et al. [19] also showed that sarcopenic obese Caucasian individuals had lower odds of having hyperinsulinemia (OR: 3.68 vs 19.6) and poor glycemic control (OR: 4.27 vs 7.98 ), concluding that sarcopenia was not a positive predictor of poor glycaemic control and thus, of diabetes.

In this regard, Lebon et al. recently concluded that in sedentary postmenopausal women lower muscle mass is not detrimental to insulin sensitivity even after adjusting for visceral fat mass [47]. Also, You et al. [48] reported that overweight and obese postmenopausal women with a higher skeletal muscle mass displayed a higher number of metabolic alterations-including impaired glucose homeostasis-compared to those with a normal metabolic profile.

In an attempt to interpret our findings, it can be argued that adipose tissue infiltration may have a major role if we consider that it is reduced in dynapenic individuals compared to non-dynapenic individuals. Recently, Barbat-Artigas et al. [39] and Goodpaster et al. [49] demonstrated that muscle quality (muscle strength/skeletal muscle mass) increased as skeletal muscle mass decreased, and the reduction in muscle mass was associated with lower muscle fat infiltration in obese individuals. This characteristic would 
predispose dynapenic people to present a better metabolic profile. Another potential explanation is that dynapenia occurs initially and mostly in peripheral upper and lower limbs (locomotor) which favor an accumulation of fat mass, more specifically intramuscular fat (IMAT), in peripheral members rather than in the abdominal area. Two studies observed an association between higher IMAT and reduced insulin resistance and an inverse association between HDL or blood pressure and IMAT in sedentary adults [50, 51].

In this sense, it was previously observed that skeletal muscle of trained endurance athletes is markedly insulin sensitive despite having an elevated intramyocelular lipid content [34] when compared to sedentary people [52]. It seems that skeletal muscle oxidative capacity (SMOC) play a role in this relationship because the SMOC is predictive of insulin action in sedentary and physically active individuals [53]. Moreover, type I muscle fibers are more sensitive to insulin compared with type II muscle fibers. Several previous studies reported that a higher proportion of type II instead of type I muscle fibers are associated with insulin resistance [54-56]. This observation is confirmed by Nyholm et al. who showed that first-degree relatives of type 2 diabetes patients who were insulin resistant had an increased number of type Ilb muscle fibers [54]. Furthermore, Lillioja et al. observed significant correlations between insulin-stimulated glucose uptake and type I (positive) and type Ilb (negative) muscle fibers in men [57]. Indeed, type II fibers are known to be positively associated with muscle strength [58]. It has also been reported that loss of leg muscle mass or strength in older adults is associated with a more prominent type II muscle fiber decline [59-61]. Therefore, it is possible that dynapenic people have a lower proportion of type II muscle fibers than non-dynapenic women, which explain the beneficial association between low muscle strength and insulin sensitivity.

This study is not without limitations. First, we used a cross-sectional approach, which does not allow us to draw conclusions regarding causal associations between dynapenia and metabolic syndrome. Second, we measured handgrip strength thus, these results may not be extrapolated to whole-body muscle strength. Third, we did not obtain any specific body composition data or muscle biopsies, so we could not confirm our hypothesis. Fourth, we did not measure the effects of dynapenia on physical function in the present study. However, we considered that many previous studies reported lower levels of muscle strength being associated with functional incapacities [26, 62]. Finally, the results of the present study should be considered preliminary, but they may hopefully stimulate interest in the characterization of dynapenic obese individuals using clinical criteria.

The major strength of this study is that a huge community-based sample of older adults was investigated and, especially persons susceptible to an increased risk of mobility disability. It is noteworthy that important confounding factors were taken into account, avoiding the influence of factors other than those of interest.

\section{CONCLUSION}

In conclusion, our results indicate that non-obese dynapenic older adults have fewer metabolic disease risk factors than non-obese non-dynapenic elderly people. Among obese, older adults, dynapenia was 
associated with lower risk of meeting metabolic syndrome criteria for waist circumference and diastolic blood pressure. Thus, in obese older adults dynapenia may have protective effects on metabolic disease risk. Our findings have clinical implications and suggest that metabolic disease risk is not increased by the presence of dynapenia in obese individuals. Further research is needed to explore the potential mechanisms underlying these observed associations. 


\section{ACKNOWLEDGEMENTS}

MAL is supported by the FRQS.

The Lifestyle Interventions and Independence for Elders Study is funded by a National Institutes of Health/National Institute on Aging Cooperative Agreement \#UO1 AG22376 and a supplement from the National Heart, Lung and Blood Institute 3U01AG022376- 05A2S, and sponsored in part by the Intramural Research Program, National Institute on Aging, NIH.

The research is partially supported by the Claude D. Pepper Older Americans Independence Centers at the University of Florida (1 P30 AG028740), Wake Forest University (1 P30 AG21332), Tufts University (1P30AG031679), University of Pittsburgh (P30 AG024827), Yale University (P30AG021342) and the $\mathrm{NIH/NCRR} \mathrm{CTSA} \mathrm{at} \mathrm{Stanford} \mathrm{University} \mathrm{(UL1} \mathrm{RR025744).}$

Tufts University is also supported by the Boston Rehabilitation Outcomes Center (1R24HD065688-01A1).

LIFE investigators are also partially supported by the following:

Dr. Thomas Gill (Yale University) is the recipient of an Academic Leadership Award (K07AG3587) from the National Institute on Aging.

Dr. Carlos Fragoso (Spirometry Reading Center, Yale University) is the recipient of a Career Development Award from the Department of Veterans Affairs.

Dr. Roger Fielding (Tufts University) is partially supported by the U.S. Department of Agriculture, under agreement No. 58-1950-0-014. Any opinions, findings, conclusion, or recommendations expressed in this publication are those of the author(s) and do not necessarily reflect the view of the U.S. Dept of Agriculture.

Dr. Michelle E. Hauser (Stanford University) is supported by the National Institutes of Health/National Heart, Lung, and Blood Institute Cardiovascular Disease Prevention Training Program grant No. 5T32HL007034-39.

Administrative Coordinating Center, University of Florida, Gainesville, FL

Marco Pahor, MD - Principal Investigator of the LIFE Study Jack M. Guralnik, MD, PhD - Co-Investigator of the LIFE Study (University of Maryland School of Medicine, Baltimore, MD) Christiaan Leeuwenburgh, PhD Connie Caudle Lauren Crump, MPH Latonia Holmes Jocelyn Lee, PhD Ching-ju Lu, MPH

Data Management, Analysis and Quality Control Center, Wake Forest University, Winston Salem, NC Michael E. Miller, PhD - DMAQC Principal Investigator Mark A. Espeland, PhD - DMAQC CoInvestigator

Walter T. Ambrosius, PhD William Applegate, MD Daniel P. Beavers, PhD, MS Robert P. Byington, PhD, $\mathrm{MPH}, \mathrm{FAHA}$

Delilah Cook, CCRP Curt D. Furberg, MD, PhD Lea N. Harvin, BS Leora Henkin, MPH, Med John Hepler, MA Fang-Chi Hsu, PhD Laura Lovato, MS Wesley Roberson, BSBA Julia Rushing, BSPH, MStat Scott Rushing, BS Cynthia L. Stowe, MPM Michael P. Walkup, MS Don Hire, BS W. Jack Rejeski, PhD Jeffrey A. 
Katula, PhD, MA Peter H. Brubaker, PhD Shannon L. Mihalko, PhD Janine M. Jennings, PhD

National Institutes of Health, Bethesda, MD

Evan C. Hadley, MD (National Institute on Aging) Sergei Romashkan, MD, PhD (National Institute on

Aging) Kushang V. Patel, PhD (National Institute on Aging)

National Heart, Lung and Blood Institute, Bethesda, MD

Denise Bonds, MD, MPH

Field Centers

Northwestern University, Chicago, IL

Mary M. McDermott, MD - Field Center Principal Investigator Bonnie Spring, PhD - Field Center CoInvestigator Joshua Hauser, MD - Field Center Co-Investigator Diana Kerwin, MD - Field Center CoInvestigator

Kathryn Domanchuk, BS Rex Graff, MS Alvito Rego, MA

Pennington Biomedical Research Center, Baton Rouge, LA

Timothy S. Church, MD, PhD, MPH - Field Center Principal Investigator Steven N. Blair, PED (University of South Carolina) Valerie H. Myers, PhD Ron Monce, PA-C

Nathan E. Britt, NP Melissa Nauta Harris, BS Ami Parks McGucken, MPA, BS Ruben Rodarte, MBA, MS, BS Heidi K. Millet, MPA, BS Catrine Tudor-Locke, PhD, FACSM

Ben P. Butitta, BS Sheletta G. Donatto, MS, RD, LDN, CDE Shannon H. Cocreham, BS

Stanford University, Palo Alto, CA

Abby C. King, PhD - Field Center Principal Investigator Cynthia M. Castro, PhD William L. Haskell, PhD Randall S. Stafford, MD, PhD

Leslie A. Pruitt, PhD Kathy Berra, MSN, NP-C, FAAN Veronica Yank, MD

Tufts University, Boston, MA

Roger A. Fielding, PhD - Field Center Principal Investigator Miriam E. Nelson, PhD - Field Center CoInvestigator Sara C. Folta, PhD - Field Center Co-Investigator Edward M. Phillips, MD

Christine K. Liu, MD Erica C. McDavitt, MS Kieran F. Reid, PhD, MPH

Dylan R. Kirn, BS Evan P. Pasha, BS Won S. Kim, BS Vince E. Beard, BS Eleni X. Tsiroyannis, BS Cynthia Hau, BS, MPH

University of Florida, Gainesville, FL 
Todd M. Manini, PhD - Field Center Principal Investigator Marco Pahor, MD - Field Center CoInvestigator Stephen D. Anton, PhD Susan Nayfield, MD

Thomas W. Buford, PhD Michael Marsiske, PhD Bhanuprasad D. Sandesara, MD Jeffrey D. Knaggs, BS

Megan S. Lorow, BS William C. Marena, MT, CCRC Irina Korytov, MD Holly L. Morris, MSN, RN, CCRC (Brooks Rehabilitation Clinical Research Center, Jacksonville, FL) Margo Fitch, PT (Brooks Rehabilitation Clinical Research Center, Jacksonville, FL) Floris F. Singletary, MS, CCC-SLP (Brooks Rehabilitation Clinical Research Center, Jacksonville, FL) Jackie Causer, BSH, RN (Brooks Rehabilitation Clinical Research Center, Jacksonville, FL) Katie A. Radcliff, MA (Brooks Rehabilitation Clinical Research Center, Jacksonville, $\mathrm{FL}$ )

University of Pittsburgh, Pittsburgh, PA

Anne B. Newman, MD, MPH - Field Center Principal Investigator Stephanie A. Studenski, MD, MPH Field Center Co-Investigator Bret H. Goodpaster, PhD Nancy W. Glynn, PhD

Oscar Lopez, MD Neelesh K. Nadkarni, MD, PhD Kathy Williams, RN, BSEd, MHSA Mark A. Newman, PhD George Grove, MS Janet T. Bonk, MPH, RN Jennifer Rush, MPH Piera Kost, BA (deceased) Diane G. Ives, MPH

Wake Forest University, Winston Salem, NC

Stephen B. Kritchevsky, Ph.D. - Field Center Principal Investigator Anthony P. Marsh, PhD - Field Center Co-Investigator Tina E. Brinkley, PhD Jamehl S. Demons, MD

Kaycee M. Sink, MD, MAS Kimberly Kennedy, BA, CCRC Rachel Shertzer-Skinner, MA, CCRC Abbie Wrights, MS Rose Fries, RN, CCRC Deborah Barr, MA, RHEd, CHES

Yale University, New Haven, CT

Thomas M. Gill, MD - Field Center Principal Investigator Robert S. Axtell, PhD, FACSM - Field Center CoInvestigator (Southern Connecticut State University, Exercise Science Department) Susan S. Kashaf, MD, MPH (VA Connecticut Healthcare System) Nathalie de Rekeneire, MD, MS Joanne M. McGloin, MDiv, MS, MBA Karen C. Wu, RN Denise M. Shepard, RN, MBA Barbara Fennelly, MA, RN

Lynne P. lannone, MS, CCRP Raeleen Mautner, PhD Theresa Sweeney Barnett, MS, APRN Sean N. Halpin, MA

Matthew J. Brennan, MA Julie A. Bugaj, MS Maria A. Zenoni, MS Bridget M. Mignosa, AS

Cognition Coordinating Center, Wake Forest University, Winston Salem, NC

Jeff Williamson, MD, MHS - Center Principal Investigator Kaycee M Sink, MD, MAS - Center CoInvestigator Hugh C. Hendrie, MB, ChB, DSc (Indiana University) Stephen R. Rapp, PhD

Joe Verghese, MB, BS (Albert Einstein College of Medicine of Yeshiva University) Nancy Woolard Mark Espeland, PhD Janine Jennings, PhD 
Valerie K. Wilson, MD

Electrocardiogram Reading Center, University of Florida, Gainesville, FL

Carl J. Pepine MD, MACC Mario Ariet, PhD Eileen Handberg, PhD, ARNP Daniel Deluca, BS

James Hill, MD, MS, FACC Anita Szady, MD

Spirometry Reading Center, Yale University, New Haven, CT

Geoffrey L. Chupp, MD Gail M. Flynn, RCP, CRFT Thomas M. Gill, MD John L. Hankinson, PhD

(Hankinson Consulting, Inc.) Carlos A. Vaz Fragoso, MD

Cost Effectiveness Analysis Center

Erik J. Groessl, PhD (University of California, San Diego and VA San Diego Healthcare System) Robert M.

Kaplan, PhD (Office of Behavioral and Social Sciences Research, National Institutes of Health)

\section{TABLES (see annexes)}




\section{REFERENCES}

1. Patti ME, Butte AJ, Crunkhorn S, et al., Coordinated reduction of genes of oxidative metabolism in humans with insulin resistance and diabetes: Potential role of PGC1 and NRF1. Proc Natl Acad Sci U S A. 2003; 100(14): 8466-71.

2. Gram B, Christensen R, Christiansen C, Gram J, et al. Effects of nordic walking and exercise in type 2 diabetes mellitus: a randomized controlled trial. Clin J Sport Med, 2010. 20(5): 355-61.

3. Ford ES. The metabolic syndrome and mortality from cardiovascular disease and all-causes: findings from the National Health and Nutrition Examination Survey II Mortality Study. Atherosclerosi. 2004; 173(2): 309-14.

4. Schrager MA, Metter EJ, Simonsick E, et al. Sarcopenic obesity and inflammation in the InCHIANTI study. J Appl Physiol (1985). 2007; 102(3): 919-25.

5. Reuter I, Mehnert $\mathrm{S}$, Leone $\mathrm{P}$, et al. Effects of a flexibility and relaxation programme, walking, and nordic walking on Parkinson's disease. J Aging Res. 2011; 232473.

6. Janssen I, Heymsfield SB, Allison DB, et al. Body mass index and waist circumference independently contribute to the prediction of nonabdominal, abdominal subcutaneous, and visceral fat. Am J Clin Nutr. 2002; 75(4): 683-8.

7. Janssen I, Baumgartner RN, Ross R, et al. Skeletal muscle cutpoints associated with elevated physical disability risk in older men and women. Am J Epidemiol. 2004; 159(4): 413-21.

8. Visser M, Goodpaster BH, Kritchevsky SB, et al. Muscle mass, muscle strength, and muscle fat infiltration as predictors of incident mobility limitations in well-functioning older persons. J Gerontol A Biol Sci Med Sci. 2005; 60(3): 324-333.

9. Cawthon PM, Fox KM, Gandra SR, et al. Do muscle mass, muscle density, strength, and physical function similarly influence risk of hospitalization in older adults? J Am Geriatr Soc. 2009; 57(8): 1411-1419.

10. Karakelides H, Nair KS. Sarcopenia of aging and its metabolic impact. Curr Top Dev Biol. 2005; 68: 123-148.

11. Atlantis E, Martin SA, Haren MT, et al. Inverse associations between muscle mass, strength, and the metabolic syndrome. Metabolism. 2009; 58(7): 1013-1022.

12. Dominguez $\mathrm{L}$, Barbagallo $\mathrm{M}$. The cardiometabolic syndrome and sarcopenic obesity in older persons. J Cardiometab Syndr. 2007, 2(3): 183-9.

13. Church TS, Earnest CP, Morss GM. Field testing of physiological responses associated with Nordic Walking. Res Q Exerc Sport. 2002; 73(3): 296-300.

14. Baumgartner RN. Body composition in healthy aging. Ann N Y Acad Sci. 2000; 904: 437-48.

15. Mannerkorpi K, Nordeman L, Cider A, Jonsson G. Does moderate-to-high intensity Nordic walking improve functional capacity and pain in fibromyalgia? A prospective randomized controlled trial. Arthritis Res Ther. 2010; 12(5): R189.

16. Aubertin-Leheudre M, Lord C, Goulet ED, et al. Effect of sarcopenia on cardiovascular disease risk factors in obese postmenopausal women. Obesity. 2006; 14(12): 2277-2283.

17. Messier V, Karelis AD, Lavoie MD, et al. Metabolic profile and quality of life in class I sarcopenic overweight and obese postmenopausal women : a MONET study. Appl Physiol Nutr Metab. 2009; 34(1): p. 18-24. 
18. Prado CM, Lieffers JR, McCargar LJ, et al. Prevalence and clinical implications of sarcopenic obesity in patients with solid tumours of the respiratory and gastrointestinal tracts: a population-based study. Lancet Oncol. 2008; 9(7): 629-35.

19. Castaneda C, Janssen I. Ethnic comparisons of sarcopenia and obesity in diabetes. Ethn Dis. 2005; 15(4): 664-70.

20. Baumgartner RN, Wayne SJ, Waters DL, et al., Sarcopenic obesity predicts instrumental activities of daily living disability in the elderly. Obes Res. 2004; 12(12): 1995-2004.

21. Breyer MK, Breyer-Kohansal R, Funk GC, et al. Nordic walking improves daily physical activities in COPD: a randomised controlled trial. Respir Res. 2010; 11: 112.

22. Goulet ED, Lord C, Chaput JP, et al. No difference in insulin sensitivity between healthy postmenopausal women with or without sarcopenia: a pilot study. Appl Physiol Nutr Metab 2007; 32(3): 426-33.

23. Stephen WC, Janssen I. Sarcopenic-obesity and cardiovascular disease risk in the elderly. J Nutr Health Aging. 2009; 13(5): 460-6.

24. Reed RL, Pearlmutter $\mathrm{L}$, Yochum $\mathrm{K}$, et al. The relationship between muscle mass and muscle strength in the elderly. J Am Geriatr Soc. 1991; 39(6): 555-561.

25. Clark BC, Manini TM. Sarcopenia $\neq$ Dynapenia. J Gerontol A Biol Sci Med Sci. 2008; 63(8): 829834.

26. Bouchard DR, Janssen I. Dynapenic-Obesity and Physical Function in Older Adults. J Gerontol A Biol Sci Med Sci. 2010; 65 (1): 71-77.

27. Barbat-Artigas S, Dupontgand S, Fex A, et al. Relationship between dynapenia and cardiorepiratory functions in healthy postmenopausal women : novel clinical criteria. Menopause, 2011. 18(4): 400-405.

28. Rantanen T, Era P, Heikkinen E. Maximal isometric strength and mobility among 75-year-old men and women. Age Ageing. 1994; 23(2): 132-7.

29. Al Snih S, Markides KS, Ottenbacher KJ, Raji MA. Hand grip strength and incident ADL disability in elderly Mexican Americans over a seven-year period. Aging Clin Exp Res. 2004; 16(6): 481-486.

30. Al Snih S, Markides KS, Ray L, et al. Handgrip Strength and Mortality in Older Mexican Americans. J Am Geriatr Soc. 2002; 50(7): 1250-1256.

31. Newman $A B$, Kupelian V, Visser $\mathrm{M}$, et al. Strength, but not muscle mass, is associated with mortality in the health, aging and body composition study cohort. J Gerontol A Biol Sci Med Sci. 2006; 61(1): 72-77.

32. Jurca R, Lamonte MJ, Church TS, et al. Associations of muscle strength and fitness with metabolic syndrome in men. Med Sci Sports Exerc. 2004; 36(8): 1301-7.

33. Sayers SP, Guralnik JM, Thombs LA, Fielding RA. Effect of leg muscle contraction velocity on functional performance in older men and women. J Am Geriatr Soc. 2005; 53(3): 467-71.

34. Goodpaster BH, He J, Watkins S, Kelley DE. Skeletal muscle lipid content and insulin resistance: evidence for a paradox in endurance-trained athletes. J Clin Endocrinol Metab. 2001; 86(12): 5755-61.

35. Martel GF, Hurlbut DE, Lott ME, et al. Strength training normalizes resting blood pressure in 65to 73-year-old men and women with high normal blood pressure. J Am Geriatr Soc. 1999; 47(10): 1215-21.

36. Stenholm S, Harris TB, Rantanen T, et al. Sarcopenic obesity: definition, cause and consequences. Curr Opin Clin Nutr Metab Care, 2008. 11(6): 693-700.

37. Senechal M, Dionne IJ, Brochu M. Dynapenic abdominal obesity and metabolic risk factors in adults 50 years of age and older. J Aging Health. 2012; 24(5): 812-26. 
38. Karelis AD, Tousignant B, Nantel J, et al. Association of insulin sensitivity and muscle strength in overweight and obese sedentary postmenopausal women. Appl Physiol Nutr Metab. 2007; 32(2): 297-301.

39. Barbat-Artigas S, Filion ME, Plouffe S, Aubertin-Leheudre M. Muscle quality as a potential explanation of the metabolically healthy but obese and sarcopenic obese paradoxes. Metab Syndr Relat Disord. 2012; 10(2): 117-22.

40. Barbat-Artigas S, Filion ME, Ringuet ME, et al. Relationship between Dynapenia and Metabolic Risk Factors in Obese Postmenopausal Women. Can J Diab. 2012; 36:269-74.

41. Pahor M, Guralnik JM, Ambrosius WT, et al. Effect of structured physical activity on prevention of major mobility disability in older adults: the LIFE study randomized clinical trial. JAMA. 2014; 311(23): 2387-96.

42. Hekler EB, Buman MP, Haskell WL, et al. Reliability and validity of CHAMPS self-reported sedentary-to-vigorous intensity physical activity in older adults. J Phys Act Health. 2012; 9(2): 225-36.

43. Troiano RP, Berrigan D, Dodd KW, et al. Physical activity in the United States measured by accelerometer. Med Sci Sports Exerc. 2008; 40(1): 181-8.

44. Folstein MF, Folstein SE, McHugh PR. "Mini-mental state". A practical method for grading the cognitive state of patients for the clinician. J Psychiatr Res. 1975; 12(3): 189-198.

45. Alley DE, Shardell MD, Peters KW, et al. Grip strength cutpoints for the identification of clinically relevant weakness. J Gerontol A Biol Sci Med Sci. 2014; 69(5): 559-66.

46. Daskalopoulou SS, Athyros VG, Kolovou GD, et al. Definitions of metabolic syndrome: Where are we now? Curr Vasc Pharmacol. 2006; 4(3): 185-97.

47. Lebon J, Aubertin-Leheudre $\mathrm{M}$, Bobeuf $\mathrm{F}$, et al. Is a small muscle mass index really detrimental for insulin sensitivity in postmenopausal women of various body composition status? J Musculoskelet Neuronal Interact. 2012; 12(3): 116-26.

48. You T, Ryan AS, Nicklas BJ. The metabolic syndrome in obese postmenopausal women: relationship to body composition, visceral fat, and inflammation. J Clin Endocrinol Metab. 2004; 89(11): 5517-22.

49. Goodpaster BH, Thaete FL, Simoneau JA, Kelley DE. Subcutaneous abdominal fat and thigh muscle composition predict insulin sensitivity independently of visceral fat. Diabetes. 1997; 46(10): 1579-85.

50. Komiya $\mathrm{H}$, Mori $\mathrm{Y}$, Yokose $\mathrm{T}$, et al. Effect of intramuscular fat difference on glucose and insulin reaction in oral glucose tolerance test. J Atheroscler Thromb. 2006; 13(3): 136-42.

51. Therkelsen KE, Pedley A, Speliotes EK, et al. Intramuscular fat and associations with metabolic risk factors in the Framingham Heart Study. Arterioscler Thromb Vasc Biol. 2013; 33(4): 863-70.

52. Jong-Yeon K, Hickner RC, Dohm GL, Houmard JA. Long- and medium-chain fatty acid oxidation is increased in exercise-trained human skeletal muscle. Metabolism. 2002; 51(4): 460-4.

53. Bruce $\mathrm{CR}$, Thrush $\mathrm{AB}$, Mertz VA, et al. Endurance training in obese humans improves glucose tolerance and mitochondrial fatty acid oxidation and alters muscle lipid content. Am J Physiol Endocrinol Metab. 2006; 291(1): E99-E107.

54. Nyholm B, Qu Z, Kaal A, et al. Evidence of an increased number of type Ilb muscle fibers in insulin-resistant first-degree relatives of patients with NIDDM. Diabetes. 1997; 46(11): 18221828.

55. Larsson H, Daugaard JR, Kiens B, et al. Muscle fiber characteristics in postmenopausal women with normal or impaired glucose tolerance. Diabetes Care. 1999; 22(8): 1330-1338.

56. Gravholt $\mathrm{CH}$, Nyholm B, Saltin B, et al. Muscle fiber composition and capillary density in Turner syndrome: evidence of increased muscle fiber size related to insulin resistance. Diabetes Care. 2001; 24(9): 1668-1673. 
Nyholm, B., et al., Evidence of an increased number of type $\mathrm{llb}$ muscle fibers in insulin-resistant first-degree relatives of patients with NIDDM. Diabetes. 1997; 46(11): p. 1822-8.

57. Lillioja S, Young AA, Culter CL, et al. Skeletal muscle capillary density and fiber type are possible determinants of in vivo insulin resistance in man. J Clin Invest. 1987; 80(2): 415-24.

58. Trappe $\mathrm{S}$, Gallagher $\mathrm{P}, \mathrm{Harber} \mathrm{M}$, et al. Single muscle fibre contractile properties in young and old men and women. J Physiol. 2003; 552(1): 47-58.

59. Lexell J, Taylor CC, Sjostrom M. What is the cause of the ageing atrophy? Total number, size and proportion of different fiber types studied in whole vastus lateralis muscle from 15- to 83-yearold men. J Neurol Sci. 1988; 84(2-3): 275-94.

60. Klitgaard $\mathrm{H}$, Mantoni M, Schiaffino $\mathrm{S}$, et al. Function, morphology and protein expression of ageing skeletal muscle: a cross-sectional study of elderly men with different training backgrounds. Acta Physiol Scand. 1990; 140(1): 41-54.

61. Verdijk LB, Jonkers RA, Gleeson BG, et al. Protein supplementation before and after exercise does not further augment skeletal muscle hypertrophy after resistance training in elderly men. Am J Clin Nutr. 2009; 89(2): 608-16.

62. Bouchard DR, Dionne IJ, Brochu M. Sarcopenic/Obesity and Physical Capacity in Older Men and Women: Data From the Nutrition as a Determinant of Successful Aging (NuAge)-the Quebec Longitudinal Study. Obesity (Silver Spring). 2009; 17(11): 2082-8. 
Table 1. Characteristics of participants according to obesity \& dynapenia classification ( $N=1453)$

\begin{tabular}{|c|c|c|c|c|c|c|}
\hline \multirow[b]{2}{*}{ Description } & \multicolumn{3}{|c|}{ Non-Obese group $(n=783)$} & \multicolumn{3}{|c|}{ Obese group $(n=670)$} \\
\hline & $\begin{array}{c}\text { Non-Dynapenic } \\
\qquad \mathrm{N}=402\end{array}$ & $\begin{array}{c}\text { Dynapenic } \\
\qquad \mathrm{N}=381\end{array}$ & P-value & $\begin{array}{c}\text { Non-Dynapenic } \\
\mathbf{N}=414\end{array}$ & $\begin{array}{c}\text { Dynapenic } \\
\mathbf{N}=\mathbf{2 5 6}\end{array}$ & P-value \\
\hline Age (yrs) & $79.2 \pm 5.1$ & $81.5 \pm 5.0$ & $<.0001$ & $76.3 \pm 4.7$ & $78.0 \pm 4.6$ & $<.0001$ \\
\hline BMI $(\mathrm{kg} / \mathrm{m} 2)$ & $26.2 \pm 2.7$ & $25.5 \pm 2.8$ & 0.002 & $35.6 \pm 4.8$ & $34.9 \pm 4.3$ & 0.042 \\
\hline Handgrip (kg) & $28.9 \pm 9.1$ & $18.7 \pm 6.5$ & $<.0001$ & $29.7 \pm 9.0$ & $18.4 \pm 5.8$ & $<.0001$ \\
\hline Handgrip/BW (kg/kg) & $0.40 \pm 0.11$ & $0.27 \pm 0.08$ & $<.0001$ & $0.30 \pm 0.08$ & $0.20 \pm 0.06$ & $<.0001$ \\
\hline Male (\%) & $138(34.3)$ & $145(38.1)$ & 0.28 & $136(32.9)$ & $77(30.1)$ & 0.45 \\
\hline White $(\%)$ & $324(80.6)$ & $331(87.1)$ & 0.014 & $291(70.6)$ & $200(78.4)$ & 0.026 \\
\hline Max educ: College or more & $279(69.4)$ & $250(66.0)$ & 0.30 & $242(58.6)$ & $159(62.1)$ & 0.37 \\
\hline $3 \mathrm{MS}(\mathrm{X} / 100)$ & $91.8 \pm 5.3$ & $91.1 \pm 5.4$ & 0.07 & $91.9 \pm 5.3$ & $92.4 \pm 5.0$ & 0.26 \\
\hline $\begin{array}{l}\text { Heart Attack: } \\
(\mathrm{n}:(\%))\end{array}$ & $34(8.5)$ & $29(7.7)$ & 0.25 & $20(4.9)$ & $25(9.8)$ & $\mathbf{0 . 0 3}$ \\
\hline $\begin{array}{l}\text { Lung Disease: } \\
(\mathrm{n}:(\%))\end{array}$ & $58(14.5)$ & $57(15.1)$ & 0.78 & $54(13.1)$ & $55(21.5)$ & 0.014 \\
\hline $\begin{array}{l}\text { Arthitis or Rhem: } \\
(\mathrm{n}:(\%))\end{array}$ & $58(14.4)$ & $68(18.1)$ & 0.17 & $85(20.6)$ & $56(22.0)$ & 0.68 \\
\hline $\begin{array}{l}\text { Diabetes: } \\
(\mathrm{n}:(\%))\end{array}$ & $87(21.8)$ & $72(19.0)$ & 0.50 & $133(32.3)$ & $81(31.6)$ & 0.96 \\
\hline Total PA per day (counts) & $95617 \pm 49660$ & $84046 \pm 51892$ & 0.005 & $94160 \pm 49862$ & $84995 \pm 43571$ & 0.029 \\
\hline Avg steps/day (n) & $2938 \pm 1573$ & $2703 \pm 1703$ & 0.07 & $2622 \pm 1327$ & $2406 \pm 1199$ & 0.056 \\
\hline Avg Min $>500$ counts/day & $55.8 \pm 36.6$ & $46.0 \pm 35.2$ & .0008 & $57.3 \pm 38.3$ & $49.8 \pm 34.4$ & 0.021 \\
\hline Total CHAMPS score & $21.6 \pm 37.1$ & $16.3 \pm 31.2$ & $\mathbf{0 . 0 3}$ & $16.7 \pm 33.1$ & $16.3 \pm 33.2$ & 0.89 \\
\hline
\end{tabular}

Table only includes LIFE study participants with sufficient grip strength and metabolic syndrome data.

Continuous measures reported as mean $\pm S D$, while categorical measures are reported as $N(\%)$. 
Table 2. Metabolic syndrome characteristics of participants according to obesity \& dynapenia classification. $N=1453$

\begin{tabular}{|c|c|c|c|c|c|c|}
\hline & \multicolumn{3}{|c|}{ Non-Obese group $(n=783)$} & \multicolumn{3}{|c|}{ Obese group $(n=670)$} \\
\hline & Non-Dynapenic & Dynapenic & & Non-Dynapenic & Dynapenic & \\
\hline Description & $\mathrm{N}=402$ & $\mathrm{~N}=381$ & P-value & $\mathrm{N}=414$ & $\mathrm{~N}=256$ & P-value \\
\hline Waist Circ $(\mathrm{cm})$ & $93.1 \pm 10.7$ & $92.2 \pm 11.2$ & 0.22 & $114.0 \pm 12.9$ & $111.2 \pm 13.1$ & 0.008 \\
\hline Systolic (mmHg) & $127.7 \pm 18.1$ & $125.9 \pm 19.6$ & 0.17 & $128.3 \pm 16.3$ & $127.4 \pm 17.8$ & 0.46 \\
\hline Diastolic (mmHg) & $67.0 \pm 10.0$ & $67.1 \pm 10.4$ & 0.91 & $70.9 \pm 10.1$ & $67.7 \pm 9.7$ & $<.0001$ \\
\hline $\mathrm{LDL}(\mathrm{mg} / \mathrm{dL})$ & $93.5 \pm 33.3$ & $92.5 \pm 32.6$ & 0.67 & $94.9 \pm 32.6$ & $92.1 \pm 31.8$ & 0.29 \\
\hline HDL (mg/dL) & $63.2 \pm 18.8$ & $64.0 \pm 19.3$ & 0.59 & $57.6 \pm 14.8$ & $58.2 \pm 15.5$ & 0.58 \\
\hline Triglycerides (mg/dL) & $112.9 \pm 53.3$ & $116.1 \pm 59.9$ & 0.44 & $131.4 \pm 59.3$ & $131.4 \pm 56.9$ & 1.00 \\
\hline Total Cholesterol (mg/dL) & $179.2 \pm 41.9$ & $179.7 \pm 41.1$ & 0.88 & $178.8 \pm 37.2$ & $176.6 \pm 38.2$ & 0.48 \\
\hline Glucose (mg/dL) & $101.2 \pm 20.6$ & $100.7 \pm 23.2$ & 0.76 & $108.7 \pm 27.4$ & $106.3 \pm 22.4$ & 0.23 \\
\hline $\begin{array}{l}\text { MetS Abdominal Obesity } \\
(\mathrm{n}(\%))\end{array}$ & $222(55.6)$ & $170(45.1)$ & 0.003 & $409(99.3)$ & $251(98.0)$ & 0.16 \\
\hline MetS Glucose (n (\%)) & $173(43.4)$ & $153(40.2)$ & 0.33 & $256(61.8)$ & $155(60.5)$ & 0.74 \\
\hline MetS HDL (n (\%)) & $74(18.5)$ & $69(18.2)$ & 0.84 & $113(27.6)$ & $69(27.6)$ & 0.98 \\
\hline MetS triglycerides (n (\%)) & $97(24.3)$ & $91(24.1)$ & 0.87 & $152(37.2)$ & $87(34.7)$ & 0.52 \\
\hline MetS Blood Pressure (n (\%)) & $301(74.9)$ & $281(73.8)$ & 0.44 & $358(86.5)$ & $208(81.3)$ & 0.09 \\
\hline Metabolic Syndrome (n (\%)) & $154(38.3)$ & $122(32.0)$ & 0.056 & $284(68.6)$ & $168(65.6)$ & 0.42 \\
\hline
\end{tabular}

Table only includes LIFE study participants with sufficient grip strength and metabolic syndrome data.

Continuous measures reported as mean $\pm S D$, while categorical measures are reported as $N(\%)$. 
Table 3: Partial correlation coefficients between grip strength and components of the metabolic syndrome.

\begin{tabular}{|c|c|c|c|c|c|c|c|c|c|c|c|c|c|c|c|c|c|}
\hline \multirow[b]{2}{*}{ Variable } & \multirow[b]{2}{*}{ Subgroup } & \multicolumn{2}{|c|}{ BMI } & \multicolumn{2}{|c|}{$\begin{array}{c}\text { Waist } \\
\text { circumference }\end{array}$} & \multicolumn{2}{|c|}{ Glucose } & \multicolumn{2}{|c|}{ Systolic BP } & \multicolumn{2}{|c|}{ Diastolic BP } & \multicolumn{2}{|c|}{ TG } & \multicolumn{2}{|c|}{ HDL } & \multicolumn{2}{|c|}{ LDL } \\
\hline & & $\begin{array}{l}\text { Part } \\
\mathbf{r}\end{array}$ & $\begin{array}{c}P \text { - } \\
\text { value }\end{array}$ & $\begin{array}{c}\text { Part } \\
\mathbf{r}\end{array}$ & $\begin{array}{c}\text { P- } \\
\text { value }\end{array}$ & $\begin{array}{l}\text { Part } \\
\mathbf{r}\end{array}$ & $\begin{array}{c}P \text { - } \\
\text { value }\end{array}$ & $\begin{array}{l}\text { Part } \\
\mathbf{r}\end{array}$ & $\begin{array}{c}P- \\
\text { value }\end{array}$ & $\begin{array}{l}\text { Part } \\
\mathbf{r}\end{array}$ & $\begin{array}{c}P \text { - } \\
\text { value }\end{array}$ & $\begin{array}{l}\text { Part } \\
\mathbf{r}\end{array}$ & $\begin{array}{c}P \text { - } \\
\text { value }\end{array}$ & $\begin{array}{l}\text { Part } \\
\mathbf{r}\end{array}$ & $\begin{array}{c}\mathbf{P}- \\
\text { value }\end{array}$ & $\begin{array}{l}\text { Part } \\
\mathbf{r}\end{array}$ & $\begin{array}{c}P- \\
\text { value }\end{array}$ \\
\hline \multirow{3}{*}{$\begin{array}{l}\text { Grip } \\
\text { Strength }\end{array}$} & All & 0.04 & 0.15 & 0.06 & 0.04 & 0.00 & 0.95 & 0.04 & 0.21 & 0.03 & 0.39 & -0.01 & 0.75 & -0.04 & 0.24 & -0.00 & 0.90 \\
\hline & Obese & 0.09 & 0.03 & 0.07 & 0.11 & -0.02 & 0.65 & 0.05 & 0.26 & -0.01 & 0.81 & -0.06 & 0.14 & -0.02 & 0.58 & -0.04 & 0.39 \\
\hline & Non-obese & 0.00 & 0.96 & 0.04 & 0.33 & 0.02 & 0.70 & 0.01 & 0.79 & 0.06 & 0.17 & 0.02 & 0.69 & -0.03 & 0.44 & 0.03 & 0.51 \\
\hline
\end{tabular}

Adjusted for age, sex, race/ethnicity, education, smoking, physical activity, comorbidities, and BMI (BMI model not adjusted for BMI) 
Table 4: Odds of meeting metabolic syndrome and its components

\begin{tabular}{|l|l|l|}
\hline \multicolumn{1}{|c}{ Outcome } & \multicolumn{1}{c|}{$\begin{array}{c}\text { Non-Obese Group } \\
\text { OR (95\% CI) }\end{array}$} & $\begin{array}{c}\text { Obese Group } \\
\text { OR (95\% CI) }\end{array}$ \\
\hline Metabolic Syndrome & $0.84(0.56,1.25)$ & $0.81(0.53,1.23)$ \\
\hline MetS Abdominal Obesity & $0.89(0.59,1.35)$ & $0.32(0.04,2.54)$ \\
\hline MetS Glucose & $0.87(0.58,1.31)$ & $0.83(0.54,1.29)$ \\
\hline MetS HDL & $1.12(0.71,1.77)$ & $0.86(0.56,1.31)$ \\
\hline MetS Blood Pressure & $0.93(0.62,1.39)$ & $0.82(0.49,1.36)$ \\
\hline MetS Triglycerides & $1.08(0.71,1.62)$ & $0.80(0.54,1.19)$ \\
\hline
\end{tabular}

*All models adjusted for age, sex, race/ethnicity, education, smoking, physical activity, comorbidities, and BMI 